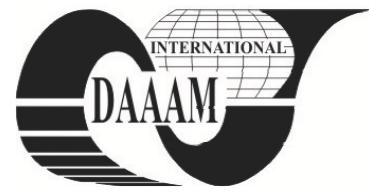

\title{
CALCULUS OF THE COEFFICIENT OF REGENERATIVE LOSSES IN STIRLING MACHINES
}

\author{
FLOREA, T[raian]; PRUIU, A[nastase]; BEJAN, M[ihai]; SERBANESCU, I[on]; CATANA, D[umitru] \& \\ VASILE, F[lorian]
}

Abstract: The coefficient of regenerative losses, $X$, includes all the losses produced by the heat transfer in the regenerator. This parameter depends on a large number of variables. Among these are piston speed, cylinder dimensions, regenerator dimensions, materials, gas proprieties, and the range of operating conditions. These variables are used in a new technique for calculating the parameter $X$.

The computed values of $X$ were compared with experimental data available in the literature. The technique for calculating the coefficient of regenerative losses $X$ proves to be accurate. This predictive capability is a powerful tool in the design of effective Stirling machines.

Key words: X coefficient, efficiency, power, Stirling engine

\section{INTRODUCTION}

This paper presents a new technique for calculating the efficiency and power of actual operating Stirling machines. This technique is based on the first law of thermodynamics for processes with finite speed. It is used in conjunction with a new $P V / P x$ diagram and a new method for determining the imperfect regeneration coefficient.

One of the objectives of this paper is to develop a method for determining the imperfect regeneration coefficient $X$, and to use it for calculating the efficiency and the power output of the Stirling engine.

The thermal efficiency is expressed as a product of the Carnot cycle efficiency and second law efficiency (Petrescu \& Harman 1996).

Initially, the thermal efficiency is written as a function of three basis parameters.

$$
\eta_{S E}=\eta_{S E} \cdot \eta_{I I, \text { irrev }}=\eta_{C C} \cdot \eta_{I I, \text { irrev }, \Delta T} \cdot \eta_{I I, \text { irrev }, X \cdot \Sigma \Delta \mathrm{P}_{\mathrm{i}}}
$$

where

$$
\eta_{C C}=1-T_{0} / T_{H, S}
$$

is the efficiency of a Carnot cycle operating between the same temperature limits as the Stirling engine.

The second law efficiency

$$
\eta_{I I, \text { irrev }, \Delta T}=1 /\left(1+\sqrt{T_{0} / T_{H, S}}\right)
$$

is determined by the irreversibility caused by the temperature difference between the heat source and the gas in the engine.

The second law efficiency

$$
\eta_{I I, \text { irrev }, X}=\left\{1+X\left(1-\sqrt{T_{0} / T_{H, S}}\right) /[(\gamma-1) \ln \varepsilon]\right\}^{-1}
$$

depends of loses in the regenerator caused by the incomplete regeneration, using of the coefficient of losses, $X$, (Florea et al., 2009).
The second law efficiency

$$
\begin{gathered}
\eta_{I I, \text { irrev }, X \cdot \Sigma \Delta P_{i}}= \\
{\left[1-\left(\sum \Delta P_{i} \cdot \Delta V_{i}\right) /\left(\eta^{\prime} P_{1} V_{1} \sqrt{T_{H, S} / T_{0} \cdot \ln \varepsilon}\right)\right]^{-1}}
\end{gathered}
$$

with

$$
\eta^{\prime}=\left(1-\sqrt{T_{0} / T_{H, S}}\right) \cdot \eta_{I I, \text { irrev }, X}
$$

considers the irreversibility losses produced by the pressure drop caused by the finite piston speed.

The optimum point of operation of the Stirling engine, from the point of view of economy, results as a trade off between efficiency and power.

The power output of the engine is:

$$
\text { Power }_{S E}=\eta_{S E} \cdot m R T_{H, g} \cdot \ln \varepsilon \cdot(w / 2 S)
$$

where $s$ is the compression ratio, $w$ is piston speed, $S$ is the stroke of the piston, and $y$ is the specific heat ratio.

\section{DETERMINATION OF LOSSES, EFFICIENCY AND POWER}

Computation of pressure losses, work losses, efficiency and power of processes revealed by the new PV/PX diagrams are made using the first law of thermodynamics for processes with finite speed. The form of first law which includes these conditions is

$$
d U=\delta Q-P_{m, i}\left(1 \pm \frac{a w}{c} \pm \frac{b \cdot \Delta P_{\text {thrott }}}{2 P_{m, i}} \pm f \cdot \Delta P_{f} \cdot P_{m, i}\right) d V
$$

When is applied to processes with finite speed the irreversible work then is

$$
\delta W_{\text {irrev }}=P_{m, i}\left(1 \pm \frac{a w}{c} \pm \frac{b \cdot \Delta P_{\text {thrott }}}{2 P_{m, i}} \pm f \cdot \Delta P_{f} \cdot P_{m, i}\right) d V
$$

The work expression for the finite speed isothermal irreversible compression process 1-2 (Fig. 1) can be integrated using the Direct Method (Petrescu et al., 2002).

The result is

$W_{1,2, \text { irrev }}=$
$\int_{1}^{2} P_{m, i d V}+\int_{1}^{2}\left[\frac{a w}{c}+\frac{b \Delta P_{\text {thrott }}}{\left(2 P_{m, c p r, i}\right)}+\frac{\Delta P_{f}}{P_{m, c p r, i}}\right] P_{m, c p r, i} d V$

The work losses can be calculated for the compression process $1-2$ by using eq. (10),

$$
\begin{gathered}
W_{12, \text { losses }}=W_{12, \text { irrev }}-W_{12, \text { rev }}= \\
=\left[\left(\frac{a w}{c}\right) P_{m, \text { cpr }, i}+\frac{b \Delta P_{\text {thrott }}}{2 \Delta P_{f}}\right]\left(V_{2}-V_{1}\right)
\end{gathered}
$$




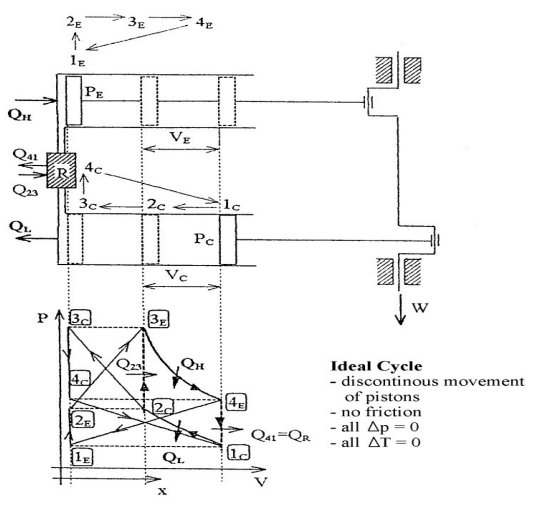

Fig. 1. The new PV/Px diagram of the ideal Stirling cycle

Computing and adding the losses produced by finite speed of the pistons, throttling of the gas through the regenerator, the mechanical friction of the entire Stirling engine cycle and introducing them into eq. (5), it becomes (Florea, 1999), (Petrescu et al., 2000):

$$
\eta_{I,, i r r e v, \sum \Delta P_{i}}=1-\frac{\left[\left(\frac{w}{w_{S, L}}\right) \gamma(1+\sqrt{\tau}) \ln \varepsilon+5 N\left(\frac{w}{w_{S, L}}\right)^{2}+\frac{3(0,94+0,045 w)}{4 \rho}\right]}{\left(\tau \eta^{\prime} \ln \varepsilon\right)}(12)
$$

The heat input during the expansion process is also irreversible because of the finite speed. In order to consider this influence, an adjusting parameter $z$ is introduced

$$
Q_{34}=z \cdot m R T_{H, g} \ln \varepsilon
$$

Finally, the real power output of the engine, eq. (7) becomes.

$$
\text { Power }_{S E, \text { irrev }}=\eta_{S E} \cdot z m R T_{H, g} \cdot \ln \varepsilon \cdot(w / 2 S)
$$

\section{A METHOD FOR X COEFFICIENT CALCULUS}

The efficiency of real Stirling machines is always less than that of the idealized Stirling cycle operating between the same temperature limits. This happens because of the heat losses that occurs in the regenerative processes. The coefficient of regenerative losses, $X$, includes all of the losses due to incomplete heat transfer in the regenerator. The analysis resulted in differential equations that were integrated. This integration is based on an analysis which gives pessimistic results, $X_{l}$ or on a linear distribution of the temperature in the regenerator matrix and gas - fig. 2 .

The last mentioned one offeres optimistic results, $X_{2}$. The resulting expressions for are:

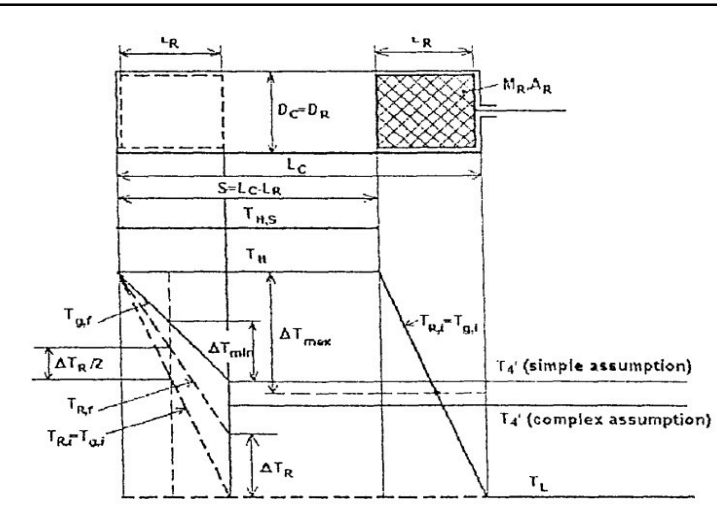

Fig. 2. Gas and matrix temperature distribution in regenerator

$$
X_{1}=\frac{1+2 M+e^{-B}}{2(1+M)} \quad ; \quad X_{2}=\frac{M+e^{-B}}{(1+M)}
$$

where

$$
\begin{gathered}
M=\frac{m_{g} c_{v, g}}{m_{R} c_{R}} ; \quad B=(1+M) \frac{h A_{R}}{m_{g} c_{v, g}} \cdot \frac{S}{w} \\
h=\frac{0,395\left(4 P_{m} / R T_{L}\right) w_{g}^{0,424} \cdot c_{p}\left(T_{m}\right) \cdot v\left(T_{m}\right)^{0,576}}{\left.(1-\tau)\left[1-\frac{\pi}{4[(b / d)-1]}\right]\right]_{R}^{0,576} \cdot P_{r}^{2 / 3}}
\end{gathered}
$$

The sensitivity of $X_{1}$ and $X_{2}$ related to operating variables, such as piston speed, was determined.

The results based on theory are correlated with experimental values using the following equation

$$
X=y X_{1}+(1-y) X_{2}
$$

where $y$ is an adjusting parameter $-0,72$.

The loss produced by incomplete regeneration determined using eq. (18) is the final loss to be considered in the analysis.

The second law efficiency caused by irreversibilities from incomplete regeneration is

$$
\eta_{I I, \text { irrev }, X}=\left[1+\left(0,72 X_{1}+0,28 X_{2}\right) \cdot \frac{\left(1-\sqrt{\frac{T_{0}}{T_{H, S}}}\right)}{\left(\frac{R}{c_{v}(T) \cdot \ln \varepsilon}\right)}\right]^{-1}
$$

The variation of the coefficient of regenerative losses with the piston speed can be revealed for several values of the analysis parameters $(d, S$, porosity)

\section{CONCLUSION}

The strong correlation between the analytical results and actual engine performance data also indicates that the Direct Method using the first law for processes with finite speed is a valid method of analysis for irreversible cycles.

\section{REFERENCES}

Florea, T. (1999). Grapho-Analytical Method for the Study of Irreversible Processes in Stirling Engines, Ph.D. Thesis, Polytechnic University of Bucharest

Florea, T.; Dragalina, A.; Costiniuc, C.; Florea, E. \& Florea, T.V. (2006). A Method for Calculating of the Coefficient for the Regenerative Losses in Stirling Machines, Acta Technica Napocensis, Series: Aplplied Mathematics and Mechanics, Vol. III, No. 49, May 2006, pp. 747-754, ISBN 1221-5872

Petrescu, S. \& Harman, C. (1996). Stirling Cycle Optimization Including the Effects of Finite Speed Operation, Proceedings of the International Conference on Efficiency, Costs, Optimization Simulation and Enviromental Aspects of Energy Systems, ECOS'96, ISBN 91-7170-664-X, pp. 167-173, edited by P. Alvfors, L. Edensten, G. Svedberg and J. Yan, Stockolm

Petrescu, S.; Harman, C.; Florea, T. \& Costea, M. (2000). Determination of the Pressure Losses in a Stirling Cycle through Use of a PV/Px Diagram, International Conference on Efficiency, Costs, Optimization and Simulation of Energy Systems, ECOS'2000, ISBN 9036514665, Entschede

Petrescu, S.; Costea, M.; Harman, C. \& Florea, T. (2002). Application of the Direct Method to irreversible Stirling cycles with finite speed. Journal of Energy Research, Vol.26, Issue7, June 2002, pp. 589-609, Online ISSN 1099114X 